\title{
Large Federal Budget Deficits: Perspectives and Prospects
}

\author{
KEITH M. CARLSON
}

Th

HE January 1975 Administration forecast of a $\$ 52$ billion deficit for fiscal 1976 generated considerable concern among the American people that the budget was "out of control." This concern took the form of uncertainty regarding expected inflation and the future course of interest rates.

From early 1975 to the present, the Federal budget (national income accounts basis) has been in deficit, averaging $\$ 67$ billion on an annual rate basis. ${ }^{1}$ At the same time, the pace of economic activity has been strong, showing an effective recovery from the recent recession. This combination of events since early 1975 - continuing large Federal deficits along with generally improving economic activity - has raised a number of questions about the role of fiscal policy in the U.S, economic system. Was the Federal deficit instrumental in promoting economic recovery, or did the recovery occur despite the deficit? What are the prospects for the future - is there no longer any need to worry about a large Federal deficit? Will it cause rising interest rates and/or lead to dislocations in the economy?

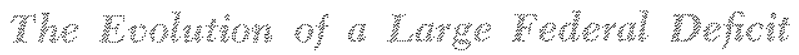

Analysis of the role of Federal deficits in influencing the movements of economic activity over recent

1Throughout this article all references to the size of the deficit are on an anmual rate basis. Also, since figures for the official (sometimes called "unified") budget are not available on a seasonally adjusted basis, most references are to the "national incone accounts budget," that is, the Federal sector of the national income accounts.

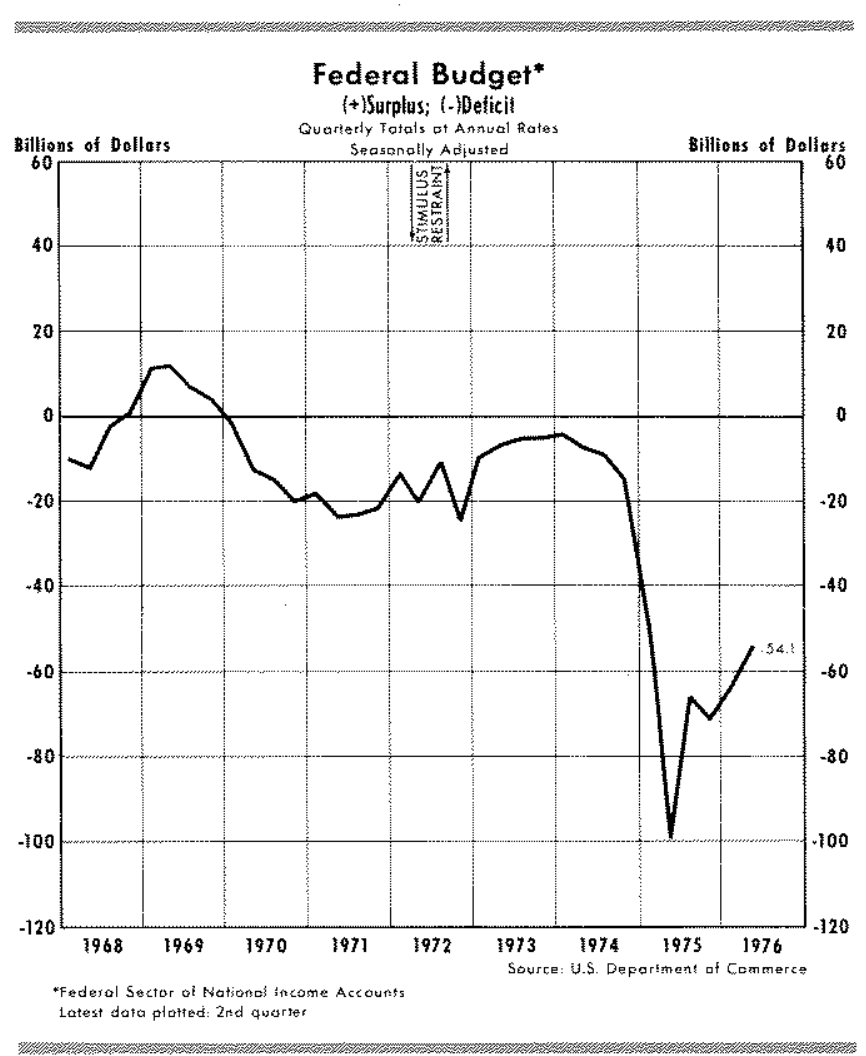

quarters requires first an understanding of exactly how the deficit came to be so large. Crucial to this understanding is the distinction between "active" and "passive" elements in the budget.

The active element in the Federal budget is defined as changes in receipts and expenditures that result from current legislation on the part of the 
Congress. The reasons for this legislation depend on a whole host of factors involving the role of Government in promoting the general welfare of the public, and subsumed under this general objective are the economic goals of full employment, price stability, and economic growth. In other words, active elements in the budget include discretionary changes in Federal expenditures and tax rates - that is, those changes in the deficit which result from current Congressional and Executive action, or possible lack of action in the case of a program which is scheduled to expire. ${ }^{2}$

The passive element in the budget, on the other hand, refers to those changes in receipts and expenditures that occur in the presence of past legislation automatically and which reflect the effects of changes in economic activity. For example, Congress and the Administration determine tax rates, and the amount of receipts collected depends on the level of income, profits and spending. ${ }^{3}$ In addition, unemployment insurance laws are written so that benefits automatically change in response to changes in economic activity. This feedback of economic activity on the budget is defined here as the "passive" aspect of the deficit.

To aid in the analysis of the factors which have contributed to the current deficit situation, the first half of 1974 is used as a reference point. In early 1974, the Federal budget was in deficit at an annual rate of $\$ 5.9$ billion, whereas in the first half of 1976 the annual rate of deficit averaged $\$ 59$ billion. To what extent did active and passive elements come into play as the budget deficit ballooned by $\$ 53$ billion?

As any analyst of current economic developments can testify, the period from early 1974 to the first half of 1976 encompasses a wide variety of economic events. Even though the recession began in late 1973, it was not until late 1974 that it took on the appearance of an aggregate demand-induced recession of

\footnotetext{
"As will become apparent later, defining the active part of the budget is much easier than developing at operational measurement of it. Even though appropriations for most projects and programs (for example, social security might be considered "permanent" in nature) have to be approved in full for any given fiscal year, there is little question that Govemment programs, once started have a momentum of their own, and Congressional and Execntive action is probably less than "fully" discretionary.

aEach of these items reflects the pace of economic activity, but with different taxes (at the Federal level) the bases for these taxes also differ. Most personal taxes are based on income, social security taxes or earnings, corporate taxes on profits, and excise taxes on spending for particular items.
}

the type experienced in past periods of U.S. history. Federal receipts did not begin to deteriorate until fourth quarter 1974, but once they started to decline, the descent continued through second quarter $1975 .^{4}$ Receipts then rebounded but expenditures rose even more, and the budget registered a deficit of $\$ 66 \mathrm{bil}-$ lion at an annual rate in third quarter 1975 . The deficit has hovered near $\$ 60$ billion through the first half of 1976.

Table I indicates what the Federal budget position for the first half of 1976 most likely would have been if the economy had continued to operate at or near 5 percent unemployment and the expenditure and revenue relationships of first half 1974 had been maintained. ${ }^{5}$ This is labeled Conditional Budget A. In other words, given the schedule of tax rates as of early 1974 and the amount of Government expenditures relative to the size of the economy, the budget would have been in surplus by $\$ 1.9$ billion in early 1976 if the economy had been at or near 5 percent unemployment.

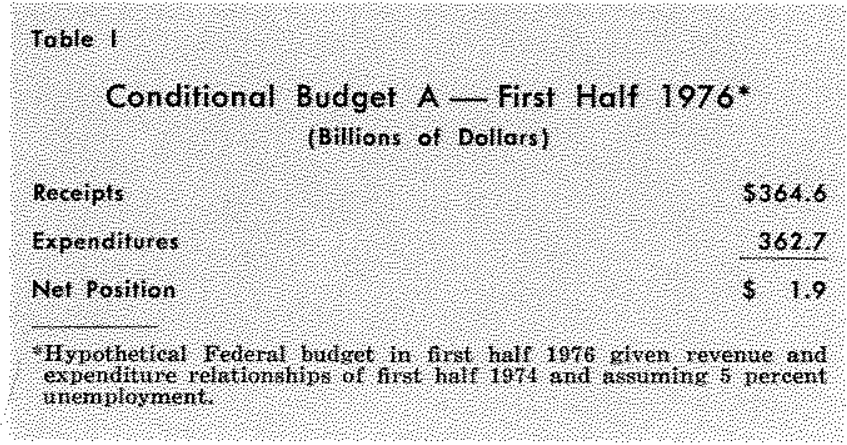

But, of course, during the early 1974 to early 1976 period the economy did not stay at 5 percent unemployment, nor did revenue and expenditure relationships remain constant. Table II gives another conditional budget which allows for only the effect on the budget of changed revenue and expenditure relationships during this two-year period. Moving from Table I (Conditional Budget. A) to Table II (Conditional Budget B) thus provides an attempt to measure the active aspect of the budget from early 1974 to early 1976. Conditional Budget $B$, based on changed tax laws and the relative size of Govern-

\footnotetext{
4The period of deterioration in receipts is confused somewhat by the tax cuts that took place in second quarter 1975. However, estimates of the amount of the tax cut indicate that, even without the tax cut, Federal receipts would have declined or at best increased only slightly in that quarter.

sNote that this definition of high-employment differs from the more common assumption of 4 percent. Structural changes in the labor force in recent years have apparently worked in the direction of raising the minimum level of unemployment that is considered consistent with relative price stability.
} 


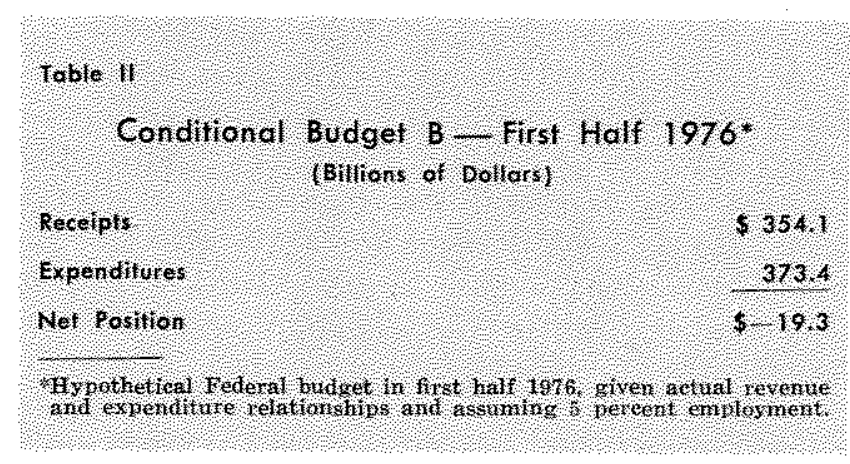

ment expenditures as they actually occurred, but still assuming 5 percent unemployment, indicates a deficit of $\$ 19.3$ billion.

The actual budget for early 1976 is shown in Table III. The figures in this table, therefore, reflect not only discretionary fiscal actions (active element) but the effects of changes in the level of resource utilization (passive element) as well. A comparison of Table II (Conditional Budget B) with Table III (Actual Budget) provides a measure of the passive element in the budget during the two-year period ending in early 1976. The level of resource utilization operated to produce a large passive element in the deficit because unemployment averaged 7.5 percent in first half 1976 - well above an assumed "high-employment" level of 5 percent unemployment.

The information in Tables I through III is combined in Table IV to provide a summary of how the deficit in early 1976 came about. The effect of discretionary fiscal actions (active element) on the deficit is derived from a comparison of Tables I and II. The difference of $\$ 21.2$ billion between Budget $A$ and Budget $B$ means an active element of that amount between the 1974 and 1976 periods. This active

6Whether the active part of the budget is classified as stimulus or restraint depends on one's interpretation of how the budget influences economic activity and how the deficit (or surplus) is financed. In general, most observers consider a positive active element as a stimulus to total spending, and a negative active element as a restraint on total spending. The procedure followed here is to define stimulus and restraint with reference to the growth of potential GNP. For example, if Federal expenditures (other than automatic changes in tnemployment benefits ) grow faster than potential GNP, this is classified as fiscal stimulus. Potential GNP is defined as that GNP consistent with 5 percent unemployment of the labor force. It should also be noted that the estimate of the amount of fiscal stimnlus depends on the period used as a reference point. If some period other than first half of 1974 were used, the estimate of fiscal stimulus would be different than $\$ 21.2$ billion.

Quite independent of the problem of measuring fiscal stimulus, there is the question of defining potential GNP. For additional discussion of how to define and measure economic petential, especially to the extent that recent disruptive events have had a bearing on these questions, see Denis S. Karnosky, "The L,ink Between Money and Prices 1971-76," this Review (June 1976), pp. 17-23.

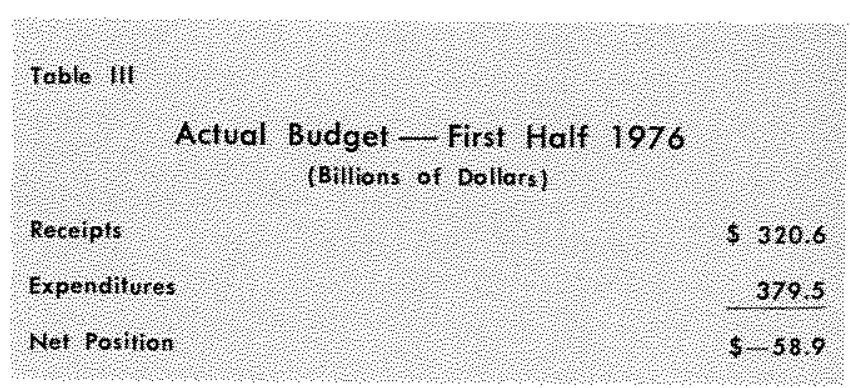

part of the budget took the form of reduced tax rates (amounting to $\$ 10.5$ billion as measured against potential GNP in early 1976) and expenditure growth $\$ 10.7$ billion) above the trend growth of potential GNP (measured in nominal terms).

The economic activity effect (passive element), as shown in Table IV, is derived from a comparison of Budget $\mathrm{B}$ and the actual budget. This economic activity effect amounted to $\$ 39.6$ billion with $\$ 33.5$ billion attributable to the effect of relatively sluggish economic activity on tax receipts and the remainder to the effect of induced expansion of expenditures (mainly unemployment compensation). ${ }^{7}$

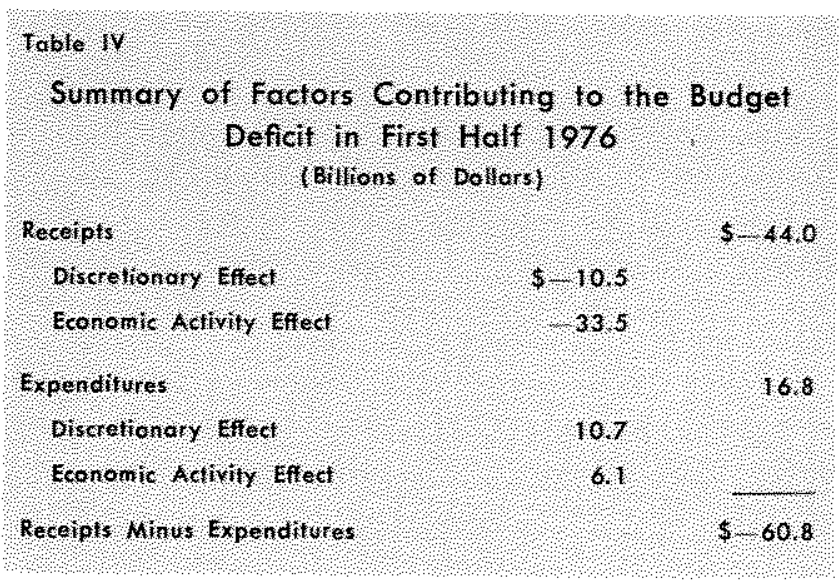

Up to this point, an explanation has not been provided as to why the distinction between active and passive elements in the deficit is important. To aid in providing such an explanation, it is necessary to examine in greater detail the relationship between $F$ ederal deficits and the money supply.

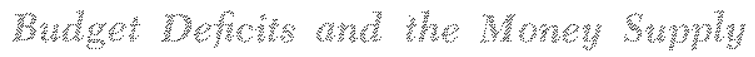

Research in recent years has established the importance of both monetary and fiscal actions in the

TEven though estimates are shown to the nearest tenth of a billion, these figures shoutd be interpreted more castally. A reugh guess would be that they are accurate within a range of phis or minus $\$ 2$ to $\$ 3$ billion. 
determination of the pace of economic activity. Differences still exist as to their relative importance, but, in general, most analysts view monetary and fiscal policy as complements. The reason they are looked upon as complements is that, historically, the two policies have tended to move together in the same direction of either stimulus or restraint.

The relation between the Federal budget and the money supply is bidirectional in the sense that changes in the Federal budget position tend to affect money growth and changes in money growth influence the budget. ${ }^{8}$ The nature of this relationship is clarified by distinguishing between active and passive aspects of the budget.

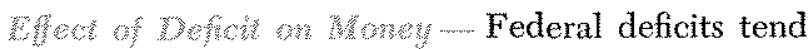
to produce pressures for monetary expansion. Increased Federal borrowing, when added to the credit demands of the private sector, places upward pressures on interest rates. The monetary authority, however, can resist these pressures for a short period of time by buying Government securities. Thus, to the extent that "low" interest rates assume a role as an objective of the monetary anthorities, deficit financing tends to accelerate the rate of monetary expansion. The degree to which any upward pressure on interest rates is counteracted by Federal Reserve actions is, of course, subject to the discretion of the monetary authority.

Instrumental in the determination of the extent to which a deficit places upward pressure on interest rates is the state of the economy, and, thus, the nature of the deficit. A predominantly active deficit, incurred when the economy is strong, provides additional demand for funds over and above the already sizeable credit demands of the private sector. In this instance there would tend to be substantial pressure on the Federal Reserve to monetize a portion of the deficit in an effort to hold interest rates down.

On the other hand, a predominantly passive deficit, resulting from a slowdown in economic activity, generates little, if any, extra demand for funds because private sector borrowings are reduced during periods of declining or weak economic activity. In this case there would tend to be less pressure on interest rates (compared to an active deficit) because

\footnotetext{
8Ths section on the interaction of monetary and fiscal actions is not meant to be comprehensive. The emphasis here is on the relationship between rinoney and budget deficits, which should not be interpreted as an exhaustive analysis of the interrelation between monetary and fiscal policy.
}

deficit financing would be replacing, rather than augmenting, private sector borrowing. ${ }^{9}$

The economic consequences of a deficit depend on the proportions which are active and passive. And such considerations enter into the determination of proper monetary and fiscal actions to be taken for purposes of achieving national economic goals. In some economic circumstances, such as recession, an active deficit is considered by many analysts to be helpful in promoting higher production and employment, although there is some dispute as to the channels by which these stimulative effects operate. A passive deficit during recession, on the other hand, need not indicate net stimulus, because, given our tax and unemployment insurance laws, both receipts and expenditures are responding automatically to the movement of economic activity,

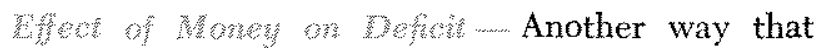
budget deficits (and surpluses) are interrelated with the money supply is of a longer-run nature. Research results show that monetary expansion has a relatively quick and long-lasting effect on nominal income, with initial effects on real output, and later effects on the price level.1.0 The effects of changes in monetary actions are translated into effects on the Federal surplus or deficit (which could be labeled as a passive response of the budget to monetary expansion) by way of nominal income. Since the base for most taxes in the Federal tax system is expressed in nominal terms, a faster growth in nominal income shows up quite quickly in a more rapid growth in Government receipts, even without any change in tax laws. In addition, with a progressive income tax, individuals are moved into higher tax brackets as income grows, resulting in higher effective tax rates in the aggregate.

Over a period of time, the rate of monetary expansion also affects the trend of Federal expenditures because the price of goods and services purchased by the Govemment moves up with everything else. Though the impact of monetary expansion (via inflation) on expenditure is probably delayed relative to that for receipts, it is just as real. There is some indication that this lag is being shortened, however,

\footnotetext{
The assessmert of the effects of deficits on interest rates also involves other factors. For example, also contributing to the behavior of interest rates in $1975-76$ was the increased supply of credit, especially of a suort-term nature.

10See, for example, Leonali C. Andersen and Keith M. Carlson, "A Monetarist Model for Economic Stabilization," this Review (April 1970), po 7-25, and Leonall C. Andersen and Denis S. Karnosky, "The Appropriate Time Frame for Contolling Monetary Aggregates: The St. Louis Evidence," in Controlling Monetary Aggregates 11 : The Interpretation, Conference sponsored by Federal Reserve Bank of Boston, Melvin Village, New Hampshire (Septembet 1972), pp. 147-177.
} 


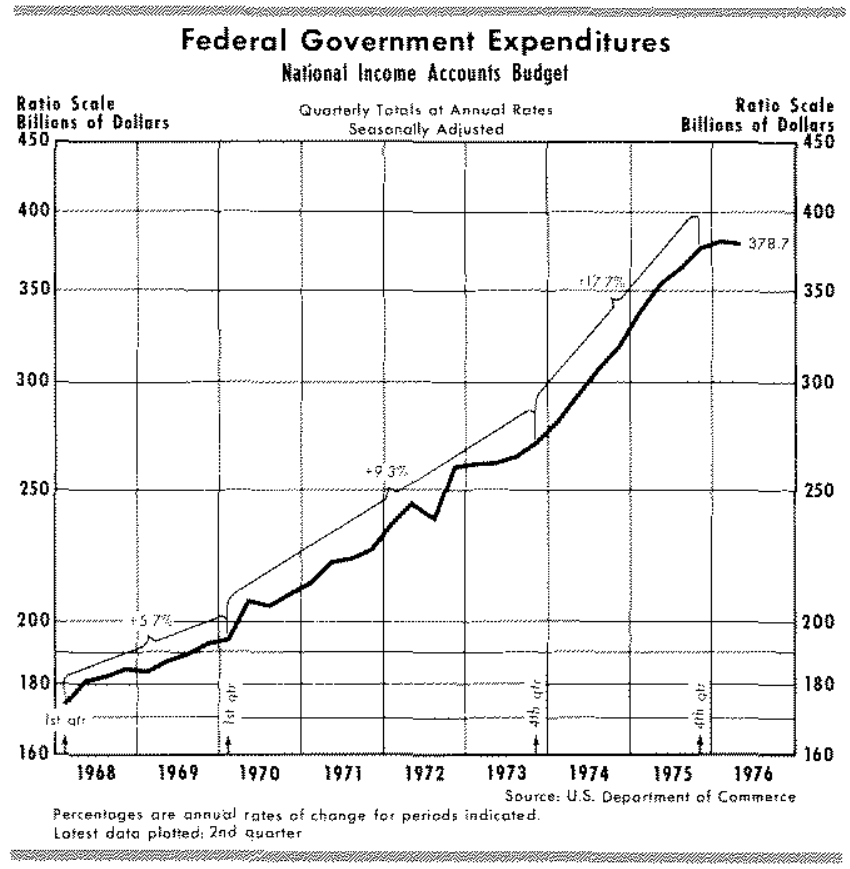

as more indexation has been built into the Government expenditure process.

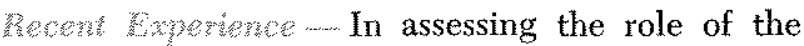
Federal deficit in the economic experience of the last year and a half, it is useful to examine data on Federal Reserve holdings of Federal debt. In early 1974, Federal Reserve holdings were 23.4 percent of the Federal debt held by the public, and have since declined to 19.6 percent in the second quarter of 1976. This sharp reversal of trend requires further explanation.

It is impossible to assess the consequences of a budget deficit without making explicit the assumptions about the way in which it is financed. And some clues about the method of financing can be gleaned from a decomposition of the deficit into its active and passive components. Furthermore, an examination of future prospects for the size of the Federal deficit requires explicit assumptions about the rate of monetary expansion mainly because of its influence on Federal receipts via the growth of nominal income.

The experience of the last year and a half has provided ample evidence in support of the notion that what matters in influencing the way in which the deficit is financed are the conditions under which the deficit occurs. The seemingly persistent occurrence of deficits in the neighborhood of $\$ 60$ billion has not wreaked havoc on the U.S. economy." Probably the

11There are some who would question the valiclity of this statement from the standpoint of increased Government control and regulation during this period. The emphasis in this article is on the effect of the deficit, not the implica- primary reason that the initially-forecast dire consequences of this large deficit have not come about is that the deficit has been predominantly passive rather than active. The job of keeping monetary expansion moderate was made relatively easy because a large portion of the deficit was of a passive nature; that is, increased Government demand for funds was offset by reduced demands by the private sector. As a result, there was little upward pressure on interest rates. In contrast to an active deficit, a passive deficit places less pressure on interest rates and thereby provides the monetary authority with greater flexibility in its attempts to achieve the goals of full employment with relative price stability.

The mere fact that this large deficit did not seem to cause great difficulty for the economy should not be interpreted to mean that large deficits are innocuous and no cause for concern in economic stabilization. The important thing to realize is that the possible impact of a Government deficit has to be viewed within the context of the prevailing economic climate. A $\$ 60$ billion deficit could inflict great harm to the economy under a different set of circumstances. An active deficit during periods of high resource utilization places upward pressure on interest rates, and to the extent that the monetary authority resists these pressures, the money supply expands more rapidly, with the eventual result being inflation.12

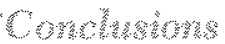

The Federal budget continues in deficit at an annual rate of near $\$ 60$ billion. From the standpoint of economic stabilization, such a deficit has not caused great harm for either financial markets or the economy as a whole because roughly two-thirds of it is attributable to relative weakness in economic activity (as measured by closeness to potential rather than the rate of advance). Recent experience appears to have demonstrated the importance of the way the deficit is financed. If financed by taxation or borrowing from the public, command over re-

tions of a growing Govemment sector. It is true that they are not independent, but concern about the size of Government should focus directly on expenditure growth rather than the deficit.

1 whe most obvious example of an active deficit cansing trouble for the economy is the fiscal 1968 deficit of $\$ 25.2$ billion. Relative to the size of the economy then, that defict was little different from the present one. But the consequences were much different because it occurred when the economy was operating at a high level of resource utiliza tion. Most, if not all, of that deficit would be classified as active in nature. Furthermore, a large proportion of that deficit was monetized, that is, accompanied by rapid monetary expansion. 
sources is shifted to the Govermment from the private sector so that inflation need not be a problem. ${ }^{\text {t3 }}$

To the extent that the active part of the deficit remains, the deficit poses an inflationary threat as the recovery continues and the economy moves back toward high employment. Consequently, the size of

13There is, however, a long-term problem that has not been mentioned heretofore. That is the effect of growing Govemment on the long-run productivity of the private sector. the budget deficit carries little meaning by itself unless it is analyzed in terms of its active and passive elements. By doing so, the deficit is thereby related to current economic conditions and one is in a better position to formulate assumptions about the rate at which it is likely to be monetized.

To the extent the Government grows, even in the absence of accommodating monetary expansion, greater infationary potential could be created via the effect on aggregate supply.

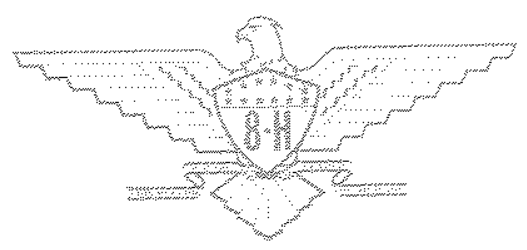

